University of Nebraska - Lincoln

DigitalCommons@University of Nebraska - Lincoln

Faculty Publications: Department of Teaching, Department of Teaching, Learning and Teacher Learning and Teacher Education

Education

2005

Explicit Reflective Nature of Science Instruction: Evolution, Intelligent Design, and Umbrellaology

Lawrence C. Scharmann

Mike U. Smith

Mark C. James

Murray Jensen

Follow this and additional works at: https://digitalcommons.unl.edu/teachlearnfacpub

Part of the Curriculum and Instruction Commons, Science and Mathematics Education Commons, and the Teacher Education and Professional Development Commons

This Article is brought to you for free and open access by the Department of Teaching, Learning and Teacher Education at DigitalCommons@University of Nebraska - Lincoln. It has been accepted for inclusion in Faculty Publications: Department of Teaching, Learning and Teacher Education by an authorized administrator of DigitalCommons@University of Nebraska - Lincoln. 
Published in Journal of Science Teacher Education 16:1 (2005), pp. 27-41; doi: 10.1007/s10972-005-6990-y Copyright (C) 2005 Springer. Used by permission.

Published online March 1, 2017

\title{
Explicit Reflective Nature of Science Instruction: Evolution, Intelligent Design, and Umbrellaology
}

\author{
Lawrence C. Scharmann, ${ }^{1}$ Mike U. Smith, ${ }^{2}$ Mark C. James, ${ }^{3}$ \\ and Murray Jensen ${ }^{4}$
}

1. Kansas State University, Manhattan, Kansas, USA

2. Mercer University, Macon, Georgia, USA

3. Northern Arizona University, Flagstaff, Arizona, USA

4. University of Minnesota, Minneapolis-St. Paul, Minnesota, USA

\begin{abstract}
The investigators sought to design an instructional unit to enhance an understanding of the nature of science (NOS) by taking into account both instructional best practices and suggestions made by noted science philosopher Thomas Kuhn. Preservice secondary science teachers enrolled in a course "Laboratory Techniques in the Teaching of Science" served as participants in action research. Sources of data used to inform instructional decisions included students' written reaction papers to the assigned readings, transcribed verbal comments made during class discussions and other in-class activities, and final reflection essays. Three iterative implementations of the instructional unit were attempted. The objectives of the study were essentially met. The instructional unit was able to provoke preservice teachers into wrestling with many substantive issues associated with the NOS. Implications concerning the design of explicit reflective NOS instruction are included.
\end{abstract}

\section{Introduction}

Few science educators would argue with the need to enhance student understanding of the nature of science (NOS). Such a goal is carefully articulated and integrated throughout recent reform documents written by the American Association for the Advancement of Science (AAAS, 1993) and National Research Council (NRC, 1996). Although these 
documents argue effectively for inclusion of NOS concepts, they do little to provide instructional methods to enhance NOS development. Understanding the NOS, however, requires that novice teachers understand such abstract ideas as the following:

- Science demands a tolerance for ambiguity and uncertainty (Moore, 1993).

- Science often develops criteria for making scientific decisions that may lead neither to truth nor match reality (Kitcher, 1985; Kuhn, 1970; Kuhn, 1993).

- Science recognizes that theories and models are, at best, useful, albeit often powerful, human-constructed tools that assist us in solving problems or puzzles (Kuhn, 1970).

Little direct research exists concerning a means by which NOS learning might be productively enhanced. In other words, in what learning activities should novice teachers engage in order to gain an understanding of abstractions such as those delineated above? Thomas Kuhn, although he never answered this question directly, spent a good part of his career providing us with a description of the characteristics that learning activities should contain to promote an understanding of the NOS. Kuhn (1993) stated that:

Four essential elements of my developed position are ... scientific terms are regularly learned in use; that use involves the description of one or another paradigmatic example of nature's behavior; a number of such examples are required for the process to work; and finally, when the process is complete, the language or concept learner has acquired not only meanings but also, inseparably, generalizations about nature. (Kuhn, 1993, p. 312)

There is, nonetheless, a growing body of evidence (loosely related to Kuhn's [1993] four essential elements) concerning what constitutes effective instructional practice for teaching and learning NOS concepts (Abd-El-Khalick, Bell, \& Lederman, 1998; Lederman, 1992). To be effective, NOS instruction should be the following:

- explicit, meaning that it should be an independent topic taught within a science course and not left to emerge implicitly through exposure to science concepts (Akerson, Abd-El-Khalick, \& Lederman, 2000; Bell, Matkins, \& McNall, 2002; GessNewsome, 2002; Scharmann \& Smith, 2001; Smith \& Scharmann, 1999);

- reflective, providing students with iterative opportunities to test out, receive feedback, and revise their NOS ideas (Akerson et al., 2000; Johnston \& Southerland, 2002; Bell et al., 2002; Scharmann, Smith, \& James, 2002) and;

- taught with or within an existing applied context, providing students with the chance to see how a science theory is applied to real-world situations (Abd-El-Khalick, 2001; Abd-El-Khalick \& Lederman, 2000; Bell et al., 2002; Dass, 2001). 


\section{Objectives of the Study}

The researchers' intentions in designing this study were to:

1. Design an explicit instructional unit aimed to enhance an understanding of the nature of science concepts among secondary science preservice teachers (PTs), accounting for both Kuhn's conditions and instructional best practices (as noted in the previous section).

2. Inform future decisions and make recommendations regarding the effectiveness of instructional sequence variations in NOS instruction.

\section{Design and Procedures}

Smith and Scharmann (1999) proposed that it might be useful (and less confrontational) to consider science and nonscience as a continuum, a proposal that is consistent with recommendations posed by Kitcher (1985), a science philosopher. With this view in mind, we proposed an activity in which secondary teachers assist students in how to use descriptors to judge the relative merits of knowledge claims instead of trying to demarcate science completely from nonscience. We further proposed that students analyze a hypothetical field of study (i.e., umbrellaology) to identify characteristics that make it more or less scientific.

Based on the empirical literature reviewed earlier and philosophical assertions made by Kuhn (1993) and Kitcher (1985), an action research project was designed. We chose action research because it is

... characterized by spiraling cycles of problem identification, systematic data collection, reflection, analysis, data-driven action taken, and, finally, problem redefinition. The linking of the terms "action" and "research" highlights the essential features of this method: trying out ideas in practice as a means of increasing knowledge about and/or improving curriculum, teaching, and learning. (Johnson, 1993, p. 1)

Essentially, action research is an iterative process used in our case to reflect upon and revise an instructional sequence designed to enhance an understanding of the nature of science among preservice secondary science teachers. The sources of data used to inform instructional decisions were students' written reaction papers to assigned readings, transcribed verbal comments made by students during whole-class discussions and other inclass activities, and final written reflection essays.

\section{Participants}

Students who were enrolled in a course entitled "Laboratory Techniques in the Teaching of Science" served as research participants. Students taking this course are typically senior undergraduates in their final semester prior to student teaching. Most of the undergraduate students participating in this study claim small rural communities as hometowns. Such 
students often take theological issues very seriously. Scharmann, lead author of this study and the instructor of the course from which these students were drawn, estimates that $95 \%$ of the science methods students with whom he has worked over the past 16 years strongly identify themselves with a Christian theological heritage. In addition, he further estimates that $25 \%$ of all his science methods students would claim to be very conservative Christians.

\section{The Course}

The course, "Laboratory Techniques in the Teaching of Science", is a companion course to more traditional methods of teaching science curriculum. The course was originally designed to address state standards that were being unmet through students' matriculation in science content coursework. The course, in complement to both science content coursework and methods of teaching science consists of four major thematic units:

1. the nature of science (NOS);

2. a lesson-plan design integrating classic laboratory techniques (e.g., serial dilution, microscopy, solution chemistry, etc.);

3. an experimental design, data collection and analysis, and graphical representation; and

4. a microcomputer-based and handheld "palm" technology laboratory (and fieldbased) experiences.

The first unit was revised to take advantage of an attempt to integrate a more effective research-based set of best practices for teaching the NOS and to model instructional activities designed to address the "History and Nature of Science" content standards from the National Science Education Standards (National Research Council, 1996). This revised unit was organized as an extended 5-E inquiry (Dougherty, 1997) lesson or unit plan (BSCS, 1997; Lawson, Abraham, \& Renner, 1989) and taught for approximately 10 instructional hours. The unit incorporated the following features:

Engagement (20 minutes): Preservice teachers were provided with a set of eight individual knowledge claims and support statements (see Table 1). Students were asked to individually place the statements on a continuum (in relation to one another) from less scientific to more scientific. The engagement activity was designed to reflect Kuhn's (1993) position, second condition, that NOS "use involves the description of one or another paradigmatic example" (p. 312). 
Table 1. Knowledge Claim Statements

A. If you break a mirror, you will have 7 years of bad luck.

B. The earth is flat. Anybody can see that!

C. Humans have a soul. I believe this because it says so in the Bible. The soul is what separates us from animals.

D. All living things are composed of one or more cells. We know this because every living thing examined to date has been found to be composed of one or more cells.

E. Taking Vitamin C prevents the common cold. Linus Pauling, the Nobel laureate who discovered the structure of Vitamin C, says it does.

F. There is a God. I know this because I can feel Him in my soul and because I depend upon Him every day.

G. If you dream of tea, someone will die. I have always heard this, and it actually happened to me one time.

$\mathrm{H}$. The rate of acceleration of all falling objects on earth is constant. Two spheres of identical diameter and volume are dropped from the top of a building; one is made of steel the other made of a plastic polymer. They both will accelerate at the same rate $\left(32 \mathrm{ft} / \mathrm{s}^{2}\right)$ same time.

Exploration (40 minutes): In groups of two or three, students were subsequently requested to compare independent responses and come to consensus on the placement of the eight statements along the continuum (see Table 2). Preservice teachers were further requested to analyze their deliberations and to delineate a set of criteria by which they judged where to place the statements on the continuum. The exploration activity was designed to reflect Kuhn's (1993) position, first condition, that "scientific terms are regularly learned in use" (p. 312).

Table 2. Knowledge Claims Activity

How do we decide that something is scientific versus something that is unscientific? This packet contains eight

(8) knowledge claims. In pairs (or groups) you should do the following:

1. Read each of the claims and accompanying statement(s) from Table 1.

2. Discuss and agree on an order to the claims, by letter, from that which you deem least to that which you deem most scientific.

3. List the order of letters below:

Less scientific <

4. Justification: explain how you decided upon this order:

Explanation (40 minutes): The instructor, Scharmann, guided preservice teachers (in wholeclass discussion and question and answer) to come to a social consensus on NOS criteria shared by all groups. This socially constructed set of criteria was then used to establish provisional guidelines for deciding what makes any individual exemplar more or less scientific in comparison to other exemplars. This activity was designed to reinforce Kuhn's (1993) first two conditions.)

Elaboration (6 hours): The preservice teachers were provided with additional information in the form of NOS readings (Backhus, 2002; Moore, 1993; Niaz, 2001; Peterson, 2002; Scharmann \& Smith, 2001; Smith \& Scharmann, 1999; Somerville, 1941) and NOS inquiry activities. In contrast to the inquiry activities to follow, these readings introduced NOS concepts explicitly. The preservice teachers were requested to provide an initial individual reflective essay for each of the readings, judging each reading on the basis of the socially 
constructed consensus criteria determined in the exploration activity and then comparing and contrasting these criteria with those issues raised by the author(s) of the readings. The instructor provided iterative feedback to individual students, by electronic mail, prior to assigning each subsequent reading. In addition, between feedback sessions, the instructor led whole-class discussions on each of the readings with specific emphasis on salient points raised by individual students in their reflective essays. Finally, students were engaged in inquiry activities designed to reflect the third condition of Kuhn's (1993) position statement (i.e., "a number of such examples are required for the process to work," p. 313), which included:

- Black Boxes: these are associated with the Models and Designs kits of the Full Option Science System (FOSS, 1992) program. In this activity, students are requested to infer the pattern of the contents of a black box without ever being able to check a correct answer. Students are typically paired to represent research teams at different universities and asked to propose a model design, provide evidence in support of their design, and suggest what further tests might be conducted to validate their model design. This activity provides an excellent extension of the necessary uncertainty associated with scientific theories based on inferential evidence and related to the readings associated with Moore (1993), Smith and Scharmann (1999), Scharmann and Smith (2001), and Niaz (2001).

- Humdingers: These are also associated with the Models and Designs kits of the Full Option Science System program (FOSS, 1992). Student teams are subsequently asked to design (i.e., engineer) a piece of equipment in which the final product both hums and dings when compared to an unseen model that performs both of the desired functions. In this case, students are eventually allowed to see the original design and make comparisons of the strengths of their own designs in relation to the original model. This activity provides a sharp contrast to the first activity by permitting students to note how pure science (i.e., a theoretical model) compares and contrasts to an "applied" science (i.e., an engineering model) and how one often drives the other. This activity is related to the readings associated with Smith and Scharmann (1999), Scharmann and Smith (2001), and Niaz (2001).

- Uncalibrated thermometers: This is an activity in which one must find a means to determine room temperature (e.g., establish reference standards, recognize measurement error, question accuracy, determine precision, recognize instrument sensitivity, etc.) on a mercury thermometer that has no markings along the length of the glass tube. Students are puzzled initially but soon begin to request ice, beakers, Bunsen burners, and so forth. This activity is related to the readings associated with Smith and Scharmann (1999), Scharmann and Smith (2001), and Niaz (2001).

Evaluation (2 hours): The culminating performance-based task, which was designed to test Kuhn's (1993) fourth condition, that is, "the language or concept learner has acquired not only meanings but also, inseparably, generalizations about nature" (p. 312), instructed preservice teachers to analyze and place the following fields of study along the less-to-more 
scientific continuum (using both the class consensus NOS criteria and those additional criteria raised in the readings as a justification for their placements):

- Umbrellaology: umbrellaology (Somerville, 1941) is a classic philosophical exercise. The author presents a case in which data are collected concerning umbrellas; the data reflect the number of umbrellas per household, selection of color by gender, and so forth. The narrator then requests the reader to determine whether or not umbrellaology represents a science.

- Intelligent design (ID): ID represents an explanation for specific biological phenomena that appear to be irreducibly complex systems and, therefore, require inherent "intelligent design." Promoters of ID further claim that it would be impossible for evolutionary processes, working via small changes accumulated over time, to construct such designs (Behe, 1996; Dembski, 1999).

- Evolution: as presented by Mayr (1991), evolutionary theory consists of the following premises:

- evolution-change over time,

- natural selection,

- modification with descent (a.k.a. common ancestry),

- multiplication of species,

$\circ$ gradualism.

Students first performed this task individually followed by subsequent small-group discussion and finally as an individual reflective essay.

\section{Findings}

The purpose of our action research was to chronicle decisions pursuant to the improvement of best practices associated with teaching about the nature of science. We describe below: (a) students prior to NOS instruction, (b) initial emergent trends among our observations during the first implementation of the revised instructional unit, (c) our second and third implementations, and (d) our postintervention emergent themes and conclusions.

\section{Students Prior to NOS Instruction}

The students participating in this study were judged by the instructor to be similar to those enrolled in the course previously. Based on student journals in which reflections were recorded throughout the duration of the class, three of the nine students (33\%) in the first implementation identified themselves as Christian conservatives compared to three of four students $(75 \%)$ in the second implementation and two of six students $(33 \%)$ in the third implementation. Prior to the onset of each of the three implementations, these students expressed strong religious views and skepticism about the knowledge claims associated with evolutionary biology. Such students typically hold strong creationist views and are resistant to learning about evolution and views of the NOS that disagree with their own. (No explicit assessment of student views of evolution, creation, and religion were obtained, as would be required in a more rigorous research study. We have found that raising this 
issue too early before an adequate foundation of NOS understanding has been laid is extremely counterproductive to the aims of instruction-many students either tune out or argue and refuse to consider viewpoints that they fear may challenge their faith.) We judged that any postinstructional assessment of intelligent design as less scientific and any criterion-based and well-reasoned assessment of umbrellaology or evolution as "more scientific" than intelligent design would likely represent desirable progress based on the absence of changes in such views among similar Christian conservative students who had previously enrolled in the course. Similarly, we sought as supportive evidence any student oral or written reflections that demonstrated disequilibrium or cognitive dissonance, which has been shown to support conceptual change, especially in relation to the study of evolution (Jensen \& Finley, 1996; Scharmann, 1993).

\section{Initial Emergent Trends}

Preservice teachers ( $n=9$; see Table 3 ) in our first implementation clearly wrestled with substantive abstractions concerning the NOS-some (quite obviously) for the first time. Some struggled (even desired) to establish a line of demarcation between science and nonscience, despite our informing them that they need not do so. Others were able to process and establish consensus criteria (e.g., observable, measurable, falsifiable-testable, role of authority, and verifiable-repeatable). Some were very articulate in their reflections.

Table 3. Postintervention (Evaluation Phase) Views of Preservice Teachers (PTs) Participating in NOS Unit Implementation $1(n=9)$

\begin{tabular}{|c|c|c|c|c|}
\hline \multirow[b]{2}{*}{ Participant } & \multicolumn{2}{|c|}{ Umbrellaology } & \multicolumn{2}{|c|}{ Intelligent design } \\
\hline & As a science & As less scientific & As a science & As less scientific \\
\hline 1 & $x$ & & $\times$ & \\
\hline 2 & & $x$ & & $x$ \\
\hline 3 & & $x$ & & $x$ \\
\hline 4 & & $x$ & $x$ & \\
\hline 5 & & $x$ & & $x$ \\
\hline 6 & & $x$ & & $x$ \\
\hline 7 & $x$ & & & $x$ \\
\hline 8 & & $x$ & $x$ & \\
\hline 9 & & $x$ & & $x$ \\
\hline
\end{tabular}

Representative quotes (from Implementation 1):

Umbrellaology as a science (22\%): using the criteria established for determining what is scientific, I have come to the conclusion that umbrellaology is a science. I will stand my ground on this matter. (PT7).

Umbrellaology as less scientific (78\%): where umbrellaology fails is in the [scientific] values it possesses. Umbrellaology has little explanatory or predictive power outside the patterns of umbrella ownership. Nor does it raise new questions that can be pursued. Therefore, umbrellaology has little value as a science. (PT5).

Intelligent design as a science (33\%): intelligent design (ID) has many characteristics that make it a science. It is based on empirical evidence and observations ... ID's claims are tentative. Therefore, it meets all of the characteristics of a science, except that it is not theologically neutral. (PT8).

Intelligent design as less scientific (67\%): although ID possesses some scientific characteristics, it does not hold up as a scientific theory. ID has the ability to explain patterns of current evidence and is based on observation. However, ID cannot make accurate predictions cannot be used to solve scientific problems. (PT2). 
Even within a relatively small group of preservice teachers there exists substantial diversity in their ability to handle abstractions. This is especially true in relation to the creationism-intelligent design/evolution issue. Students also either directly remarked that they felt uncertain what the knowledge claims made by intelligent design (ID) advocates were or made assumptions as to what they supposed its advocates claimed. In both instances, it was clear in reading student reflections that more than a few of them did not know what the knowledge claims of ID were.

\section{Second Implementation}

To clarify the impact of the engagement activity in establishing an explicit-reflective instructional environment, the knowledge claims activity was moved to the evaluation phase along with a critical reading (Smith \& Scharmann, 1999), that is, as culminating tasks, and the second iteration of the unit was administered to a different group of students $(n=4)$ enrolled in the same class (see Table 4). NOS concepts were introduced implicitly through only the use of the inquiry activities. The same readings were assigned according to which students wrote reaction papers; however, criteria for the continuum were not established prior to the students' written reflections. Although students seemed to become more aware of implied NOS concepts throughout the second implementation of the unit, this second group of students seemed less cognizant of how science establishes and uses criteria in making decisions about knowledge claims. As a result of a delay in introducing the critical article (Smith \& Scharmann, 1999), students also appeared to become less focused on NOS concepts and more attentive to questions concerning science-religion and scientific-evidence issues. Without gaining a different NOS perspective, which the critical article (Smith \& Scharmann, 1999) introduces, second-implementation students behaved in a manner similar to classes of students who completed the course prior to introducing the revised instructional unit. In other words, not only does the article make a potential difference but its placement in the instructional unit does also. 
Table 4. Postintervention (Evaluation Phase) Views of Preservice Teachers (PTs) Participating in NOS Unit Implementation $2(n=4)$

\begin{tabular}{lccccc}
\hline & \multicolumn{2}{c}{ Umbrellaology } & & \multicolumn{2}{c}{ Intelligent design } \\
\cline { 2 - 3 } \cline { 5 - 6 } Participant & As a science & As less scientific & & As a science & As less scientific \\
\hline 10 & $\times$ & $\times$ & & & \\
11 & & & & $\times$ & \\
12 & $\times$ & & & $\times$ & \\
13 & $\times$ & & & & \\
\hline
\end{tabular}

Representative quotes (from Implementation 2):

Umbrellaology as a science (75\%): before this class, I always thought the point of teaching science was to teach the facts of science which had already been discovered - that science was a "right or wrong" kind of subject. Now I am thinking about it in a totally different way. (PT10).

Umbrellaology as less scientific (25\%): giving priority to evidence allows students to develop and evaluate their explanations to their questions. This is important since science distinguishes itself from other ways of knowing through its reliance on empirical evidence. Allowing learners to communicate their ideas with one another provides for further skeptical review and the opportunity for other scientists to use their explanations in work on new questions. (PT11).

Intelligent design as a science (75\%): it [evolution] should be open to criticism in order to identify faulty reasoning, point out statements which go beyond the evidence, and suggest alternative explanations (like ID). Scientific experiments must involve student questioning and trying to come up with their own conclusions. Unquestioning acceptance of conceptual givens provided by a teacher discourages students from raising critical questions. (PT13).

Intelligent design as less scientific (25\%): what are three characteristics that make a statement less scientific? First, taking a theological position; second, valuing authority over evidence; and third, relying on faith rather than reason. It [ID] is not necessarily untrue - it is just that science cannot test the truth of some statements. (PT11).

Thus, there were two significant consequences noted in shifting the knowledge claims activity from the engagement phase. First, consistent with Kuhn's (1993) stated conditions, explicit early introduction of NOS concepts is critical. Second, it appears to be important that students address science and religion issues earlier; students in the second implementation dealt with these issues for the first time as they were trying to make comparisons between evolution, ID, and umbrellaology.

\section{Third Implementation}

In full recognition of the crucial role of introducing NOS concepts early and explicitly, the knowledge claims activity was returned to the engagement phase in a third trial of this instructional unit. To more adequately address student concerns regarding the actual claims attributed to intelligent design, an additional reading was also added. In this article, Peterson (2002) introduces the major knowledge claims made by individuals recognized as the leading advocates for ID. From a theological vantage point, Peterson proceeds to dismiss the scientific validity of ID while simultaneously recognizing ID's poor theological standing. The negative review of ID was all the more striking to students, given that the author was not a scientist, but was, instead, a conservative theologian. Finally, consistent with suggestions made by students in the first implementation, additional reflection time was allotted prior to submission of the final reactions to evolution, ID, and "Umbrellaology" in the evaluation phase. 
At the conclusion of the NOS unit, third-implementation students $(n=6)$ exhibited signs of greater nascent intellectual acuity in recognizing the inadequacy of their initial NOS views than did students who participated in the first and second implementations. This additional maturity was manifest in a recognition by several students that not only were their initial views inadequate, but their views needed to change in order to more appropriately address NOS concepts with their future students. Third-implementation students, in addition, were able to state more articulate reflections concerning the degree to which ID and umbrellaology met or failed to meet scientific criteria (see Table 5).

Table 5. Postintervention (Evaluation Phase) Views of Preservice Teachers (PTs) Participating in NOS Activity Implementation $3(n=6)$

\begin{tabular}{|c|c|c|c|c|c|}
\hline \multirow[b]{2}{*}{ Participant } & \multirow[b]{2}{*}{ As a science } & \multicolumn{2}{|c|}{ Umbrellaology } & \multicolumn{2}{|c|}{ Intelligent design } \\
\hline & & Uncertain & As less scientific & As a science & As less scientific \\
\hline 14 & & & $\times$ & & $\times$ \\
\hline 15 & & & $\times$ & & $\times$ \\
\hline 16 & & $\times$ & & & $\times$ \\
\hline 17 & & & $\times$ & & $\times$ \\
\hline 18 & & & $\times$ & & $\times$ \\
\hline 19 & & & $\times$ & & $\times$ \\
\hline
\end{tabular}

Representative quotes (from Implementation 3):

Umbrellaology as a science ( $0 \%)$.

Uncertain regarding umbrellaology (25\%): I think that a strong case has been built for why it "appears" to be a science. However, I think that the separation of science and non-science is too vague to make a solid determination. In other words, what really makes a science and what does not is still a question in my mind. (PT16).

Umbrellaology as less scientific (75\%): my initial reaction to the first article [umbrellaology] was "you have to be kidding," and I know that is what the article is made to do. But as I read the article, it appeared there could be a case made to its validity (e.g., testable, empirical, repeatable, etc.). Not a very strong case, but a case nonetheless. (PT19).

Intelligent design as a science ( $0 \%)$.

Intelligent design as less scientific (100\%): intelligent design is far less scientific. It is not based on observation and has virtually no predictive power. It has a high degree of fideism. That is, it relies heavily on faith rather than reason. Almost everything in ID would be ranked at the extreme "less scientific" side on a continuum. (PT18). Intelligent design, in my opinion, is at the lowest end of the scientific continuum. I base this opinion on the fact that I found very few instances where it fit the authors' suggestions of things that are more scientific. Really the only qualifications that it meets are that it is based on observation, that it "claims" to find out about the natural world, and that it deals with things that can be perceived. I do not feel that these few traits allow ID to be considered a true science. (PT14).

\section{Postintervention Emergent Themes}

An examination of student evaluation-phase analyses demonstrated the following results. In the first and second implementations of the NOS unit, all six students claiming a conservative Christian theology at the outset of the NOS unit also claimed ID as a science at the close of the NOS unit. In contrast, in the third implementation of the NOS unit, none of the preservice teachers (including the two students who claimed to be Christian conservatives at the outset of the study) argued that ID is a science and all recognized 
evolution as clearly more scientific than ID at the close of the NOS unit. This final group illustrates the potential success of the revised unit in enhancing student understandings of the NOS.

\section{Conclusions}

The objectives of the study were essentially met. The organization of the instructional unit, as designed and subsequently revised, was able to provoke preservice teachers into wrestling with many substantive issues and abstractions associated with the NOS. Writing samples from PTs in each of the implementations of the NOS instructional unit frequently evidenced disequilibrium or cognitive dissonance, which is conducive to conceptual changes. This study also suggests the following:

- Consistent with recent literature and based on the instructor's 16 years of experience teaching this course, an understanding of NOS concepts is enhanced when NOS concepts are introduced in an explicit-reflective manner. Multiple opportunities for student reflection must occur over time.

- The instructional unit designed to introduce NOS concepts must be carefully sequenced. An introduction of the more scientific to less scientific continuum and criteria to determine the placement of knowledge claims along this continuum presented students a fruitful context in which to consider topics such as evolution, intelligent design, and umbrellaology. Using a continuum approach to introduce NOS issues (Kitcher, 1985) permits students to label such constructs as ID as less scientific without forcing them to necessarily dismiss ID entirely. The approach also provides students with a place to stand in relation to what many students initially perceive to be an either/or dilemma (Perry, 1970; Scharmann, 1993). Thus, the continuum approach is both philosophically and pedagogically fruitful. The approach described here also meets each of the conditions for successfully introducing NOS concepts, as explicated by Kuhn (1993).

- It is important in NOS instruction to permit the science-religious issue to surface immediately and be respectfully discussed throughout the duration of the instructional unit. This conclusion is consistent with findings reported by Dagher and BouJaoude (1997) and Woods and Scharmann (2001), especially when addressing evolutionary theory.

\section{Suggestions for Further Study}

The critical issues discussed in this paper are germane to the success of any science methods course for preservice teachers. While the authors are encouraged by the trends observed in this study, we recognize that, as with any action research study, it may be inappropriate to generalize from this study to other populations. We, therefore, advocate two distinct research avenues to advance pedagogical knowledge in this area.

First, we invite science methods instructors to implement the instructional unit designed for the third implementation in their classrooms and to collect and forward to us 
data collected from their students. By analyzing the data from a large number of implementations conducted in various settings with various populations, the validity of conclusions drawn in this study will be increased and generalizability enhanced. This process has already begun at one university where the unit was administered, with slight modifications, to secondary science methods students. In that course, preservice teachers have reflected on their 5-E (Dougherty, 1997) NOS learning experience in a threaded web-based discussion. We eagerly await the results of that study.

Second, a rigorous, experimentally controlled study utilizing more standardized measures and a larger sample size is needed. A pre- and post-test measuring attitudes toward, and understanding of, NOS would provide valuable triangulation to any conclusions that might be drawn. Such a study could use the current investigation as a basis to create the necessary qualitative codings and protocols. An identification of the characteristics of different student populations could lead to further insight into how best to effect the greatest changes in understanding of specific groups about the NOS. Of particular interest are subjects with strong-fundamentalist aversions to teaching evolution. Preservice biology teachers with these inclinations certainly exist at each of our institutions and, therefore, have the greatest potential for positive change.

\section{References}

Abd-El-Khalick, F. (November 2001). Do history of science courses influence college students' views of nature of science? Paper presented at the 6th Annual International Conference of History, Philosophy, and Science Teaching, Denver, CO.

Abd-El-Khalick, F., Bell, R. L., \& Lederman, N. G. (1998). The nature of science and instructional practice: Making the unnatural natural. Science Education, 82, 417-436.

Abd-El-Khalick, F., \& Lederman, N. G. (2000). The influence of history of science courses on students' views of nature of science. Journal of Research in Science Teaching, 37, 1057-1095.

Akerson, V. L., Abd-El-Khalick, F., \& Lederman, N. G. (2000). Influence of reflective explicit activitybased approach on elementary teachers' conceptions of nature of science. Journal of Research in Science Teaching, 37, 295-317.

American Association for the Advancement of Science. (1993). Benchmarks for science literacy. New York: Oxford University Press.

Backhus, D. A. (2002). It's not just a theory. The Science Teacher, 69(4), 44-47.

Behe, M. J. (1996). Darwin's black box. New York: Touchstone.

Bell, R. L., Matkins, J. J., \& McNall, R. L. (April 2002). Impacts of contextual and explicit instruction on preservice elementary teachers' understandings of the nature of science. Paper presented at the Annual Meeting of the American Educational Research Association, New Orleans, LA.

BSCS. (1997). BSCS biology: A human approach. Dubuque, IA: Kendall/Hunt.

Dagher, Z. R., \& BouJaoude, S. (1997). Scientific views and religious beliefs of college students: The case of biological evolution. Journal of Research in Science Teaching, 34, 429-445.

Dass, P. M. (November 2001). Understanding of the nature of scientific enterprise (NOSE) through a discourse with its history: The influence of an undergraduate "history of science" course. Paper presented at the 6th Annual International Conference of History, Philosophy, and Science Teaching, Denver, $\mathrm{CO}$. 
Dembski, W. A. (1999). Intelligent design. Downer's Grove, IL: Intervarsity Press.

Dougherty, M. J. (1997). Formative assessment. The Science Teacher, 64(6), 29-33.

FOSS (1992). Full option science system-Models and designs module. Chicago. Encyclopaedia Britannica Educational Corporation.

Gess-Newsome, J. (2002). The use and impact of explicit instruction about the nature of science and science inquiry in an elementary science methods course. Science Education, 11, 55-67.

Jensen, M. S., \& Finley, F. N. (1996). Changes in students' understanding of evolution resulting from different curricular and instructional strategies. Journal of Research in Science Teaching, 33, 879-900.

Johnson, B. (1993). Teacher-as-researcher. ERIC Digests. Retrieved March 24, 2004, from http://ericfacility .net/ericdigests/ed355205.html.

Johnston, A. T., \& Southerland, S. A. (April ,2002). Conceptual ecologies and their influence on nature of science conceptions: More dazed and confused than ever. Paper presented the Annual Meeting of the American Educational Research Association, New Orleans, LA.

Kitcher, P. (1985). Good science, bad science, dreadful science, and pseudoscience. Journal of College Science Teaching, 14, 168-173.

Kuhn, T. S. (1970). The structure of scientific revolutions (2nd ed.). Chicago: University of Chicago Press.

Kuhn, T. S. (1993). Afterwords. In Paul Horwich (Ed.), World changes. Thomas Kuhn and the nature of science (pp. 311-341). Cambridge, MA: MIT Press.

Lawson, A. E., Abraham, M. R., \& Renner, J. W. (1989). A theory of instruction: Using the learning cycle to teach science concepts and thinking skills. Columbus, $\mathrm{OH}$ : National Association for Research in Science Teaching.

Lederman, N. G. (1992). Students and teachers conceptions of the nature of science. A review of the research. Journal of Research in Science Teaching, 29, 331-359.

Mayr, E. (1991). One long argument. Cambridge, MA: Harvard University Press.

Moore, R. (1993). Science \& uncertainty. American Biology Teacher, 55, 4.

Niaz, M. (2001). Understanding nature of science as progressive transitions in heuristic principles. Science Education, 85, 684-690.

National Research Council. (1996). National science education standards. Washington, DC: National Academy Press.

Perry, W. G. (1970). Intellectual and ethical development. New York: Holt, Rinehart, \& Winston

Peterson, G. R. (2002). The intelligent-design movement: Science or ideology? Zygon, 37(1), 7-23.

Scharmann, L. C. (1993). Teaching evolution: Designing successful instruction. American Biology Teacher, 55, 481-487.

Scharmann, L. C., \& Smith, M. U. (2001). Further thoughts on defining versus describing the nature of science: A response to Niaz. Science Education, 85, 691-693.

Scharmann, L. C., Smith, M. U., \& James, M. C. (April, 2002). Novice science teachers' understanding of the nature of science: An action research project. Paper presented at the Annual Meeting of the National Association for Research in Science Teaching, New Orleans, LA.

Smith, M. U., \& Scharmann, L. C. (1999). Defining versus describing the nature of science: A pragmatic analysis for classroom teachers and science educators. Science Education, 83, 493-509.

Somerville, J. (1941). Umbrellaology, or, methodology in social science. Philosophy of Science, 8, 557-566.

Woods, C. S., \& Scharmann, L.C. (2001). High school students' perceptions of evolutionary theory. Electronic Journal of Science Education, 6(2). Retrieved March 24, 2004, from http://unr.edu/homepage/ crowther/ejse/woodsetal.html. 